\title{
Transition from mining with caving to mining with cemented backfilling - a case study
}

VA Eremenko Institute of Comprehensive Exploitation of Mineral Resources, Russia

BB Tatarnikov EVRAZRUDA, Russia

AA Eremenko Chinakal Institute of Mining, Russia

EN Esina Institute of Comprehensive Exploitation of Mineral Resources, Russia

\begin{abstract}
The authors present the actual scenario of transition from mining with caving to mining with backfilling in a deep level ore mine exposed to high horizontal stress of $5 \mathrm{\gamma H}$. Backfill mixture is prepared on the backfill preparation plant of the mine using the local material.
\end{abstract}

\section{$1 \quad$ Introduction}

The Tashtagol iron ore mine is situated in West Siberia, an area with active modern tectonic activity. Horizontal stress is 2.5 times higher than vertical stress in the rock mass out of stoping operations and is fivefold the vertical stress in the area of productive excavation as illustrated in Figure 1 (Eremenko et al. 2012). Stoping has reached the depth of $1 \mathrm{~km}$ (Bronnikov et al. 1982). The deep level mining undergoes significant increase in ground pressure (Eremenko et al. 2008).

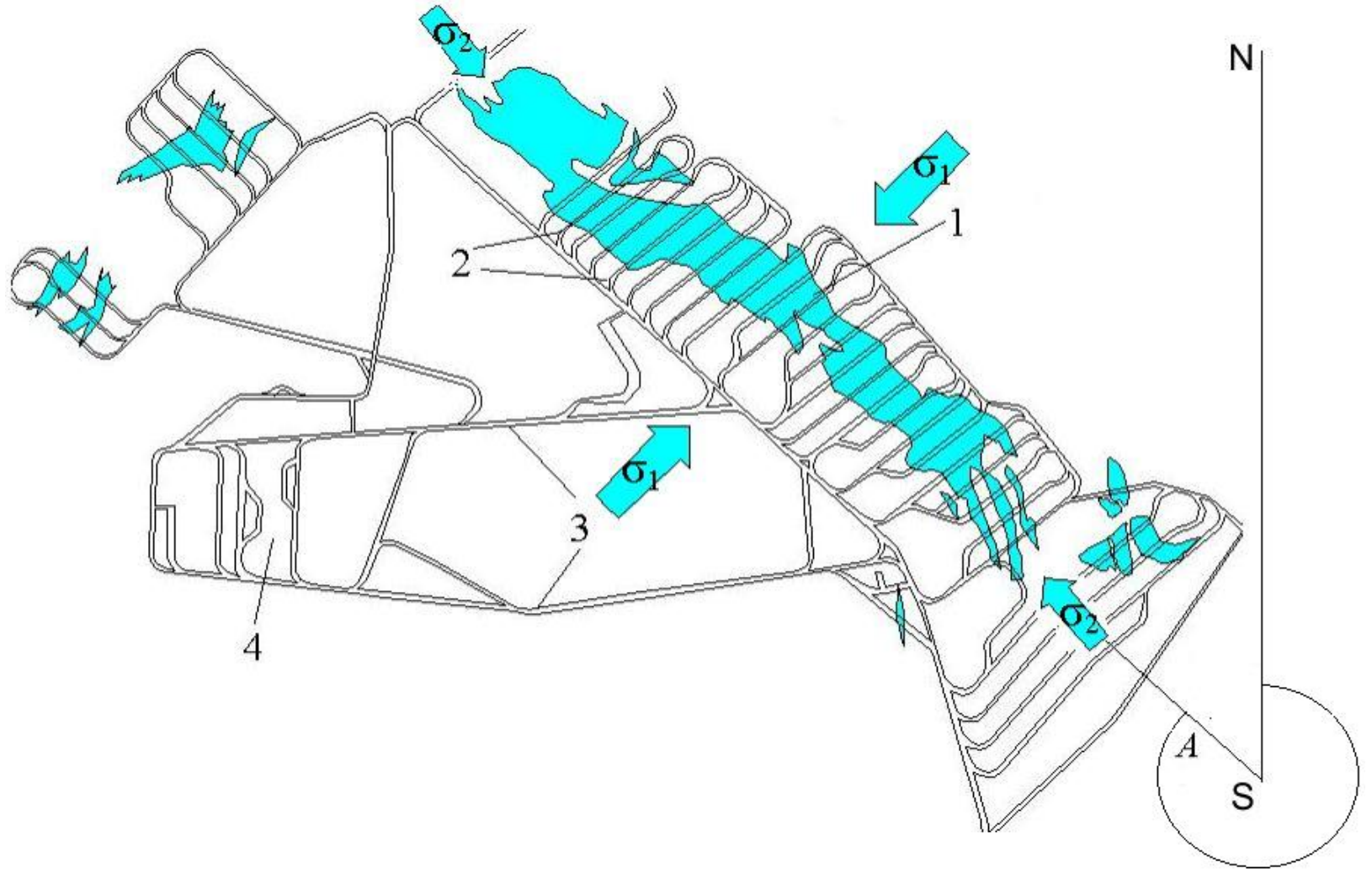

Figure 1 Tashtagol Mine Level 750 m, plan view; (1) orebody; (2) crosscuts; (3) cross measures; (4) shaft station;

$\sigma_{1}=5 \gamma \mathrm{H}-$ maximum principal horizontal stress in the stoping area; $\sigma_{2}=3.5 \mathrm{\gamma H}-$ 
principal intermediate stress; $A=315^{\circ}$ - azimuth of the maximum natural compression stress (out of the stoping area)

In mining with caving, stoping voids are filled with broken caved rock (Figure 2).

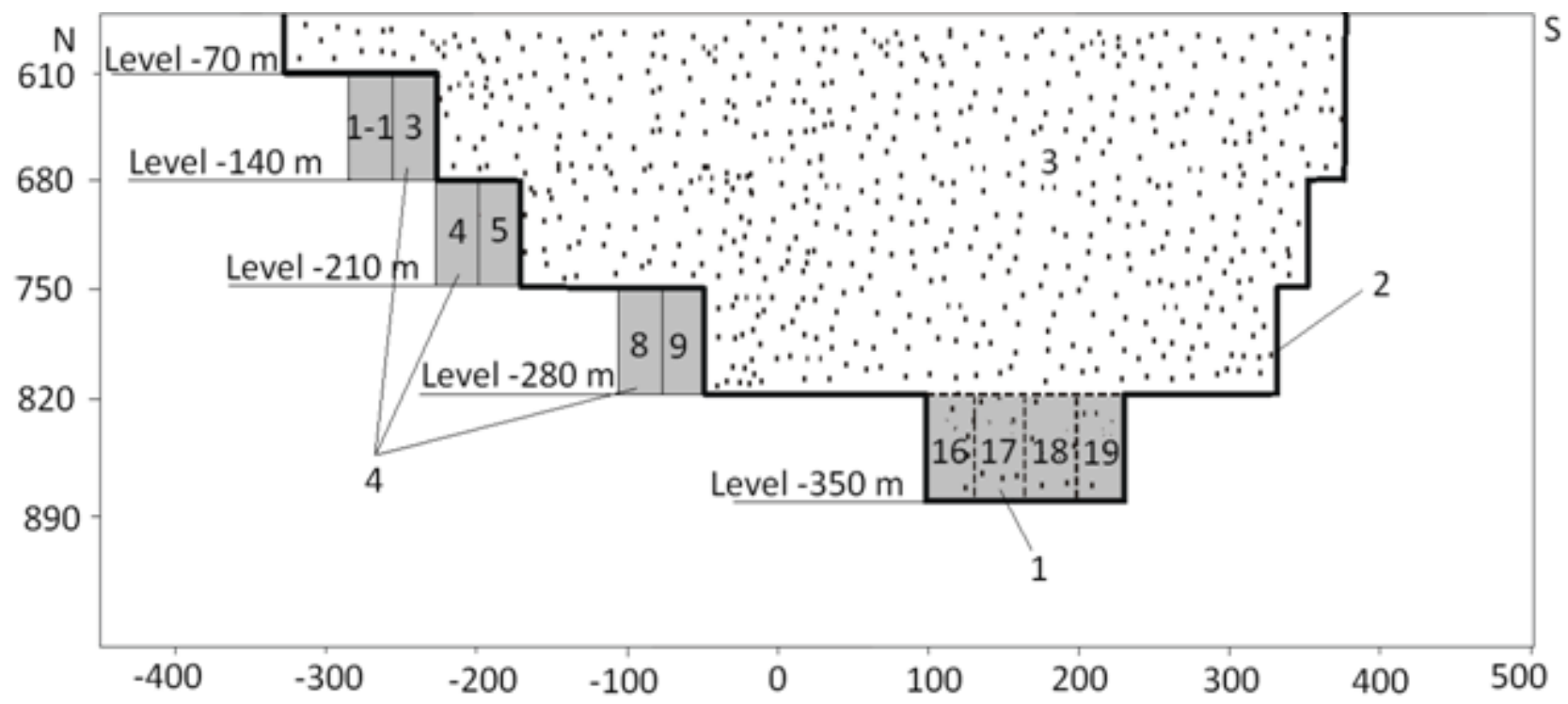

Figure 2 Schematically, Tashtagol Mine, actual stoping area (side view). Stoping is advanced from the centre sideward, concurrently on four levels; apart from the bottom level, three levels on the southern side have been mined out; on the northern side, all four levels are under mining; (1) uncovering blocks (first, block 17 is blasted and extracted, then blasting and extraction of blocks 16, 18, 19, etc.); (2) boundary of the mined out void; (3) mined out void filled with caved rocks; (4) extraction blocks $1-1,3, \ldots 19$

The sub level caving method used in Tashtagol Mine is illustrated in Figure 3. First, a rock block 27-30 m wide and $60-90 \mathrm{~m}$ high is prepared (70 $\mathrm{m}$ in the case discussed); the width of the rock block equals the thickness of the orebody, which varies from 50-100 m. During rock block preparation, a haulage crosscut is driven as well as an undercutting (cushioning) crosscut over the drawpoints, and a drilling crosscut (for vertical blasthole drilling) below the upper haulage level are driven. The block is caved by delayed action explosion of fans of vertical parallel explosive charges $105 \mathrm{~mm}$ in diameter: first the charges in the middle of the block are initiated (delay interval is $0.1-0.5 \mathrm{~ms}$ ), then marginal charges are set off (delay interval is 0.6-1.0 ms). Blasting is oriented toward the pre-driven cushion crosscuts (or cushion chambers, their amount is defined by the size of the rock block to be blasted - the thicker is the orebody, the larger is the rock block), toward the balancing room provided by the undercutting level and toward previously blasted but not excavated neighbour rock block (to prevent flying off of rock fragments). Explosive is 100-500 $t$ in weight, which is also governed by the size of the rock block to be blasted; powder factor is $0.3-0.6 \mathrm{~kg}-\mathrm{t}$ per block. Ore is loaded from the bottom of the block to cars by shakers. After the ore is removed the mined out void is filled with caved rocks from above. With this method, the ore loss is $10-12 \%$ and ore dilution is $25-30 \%$. The primary concentration method of this black iron ore is magnetic separation. The rock mass is drastically affected by blasting.

At present in the Tashtagol Mine, the best part of iron ore occurs in safety pillars. The rest of the reserves are under caving with levels $70 \mathrm{~m}$ high. The stoping has approached the boundary of the protective pillars, which complicates geomechanical situation in the mine. Transition to mining with backfill appears to be infeasible as mined out voids to be filled with cemented backfill incur a risk of collapse inasmuch as the boundary of caving and the boundary of the safety pillars nearly coincide. 

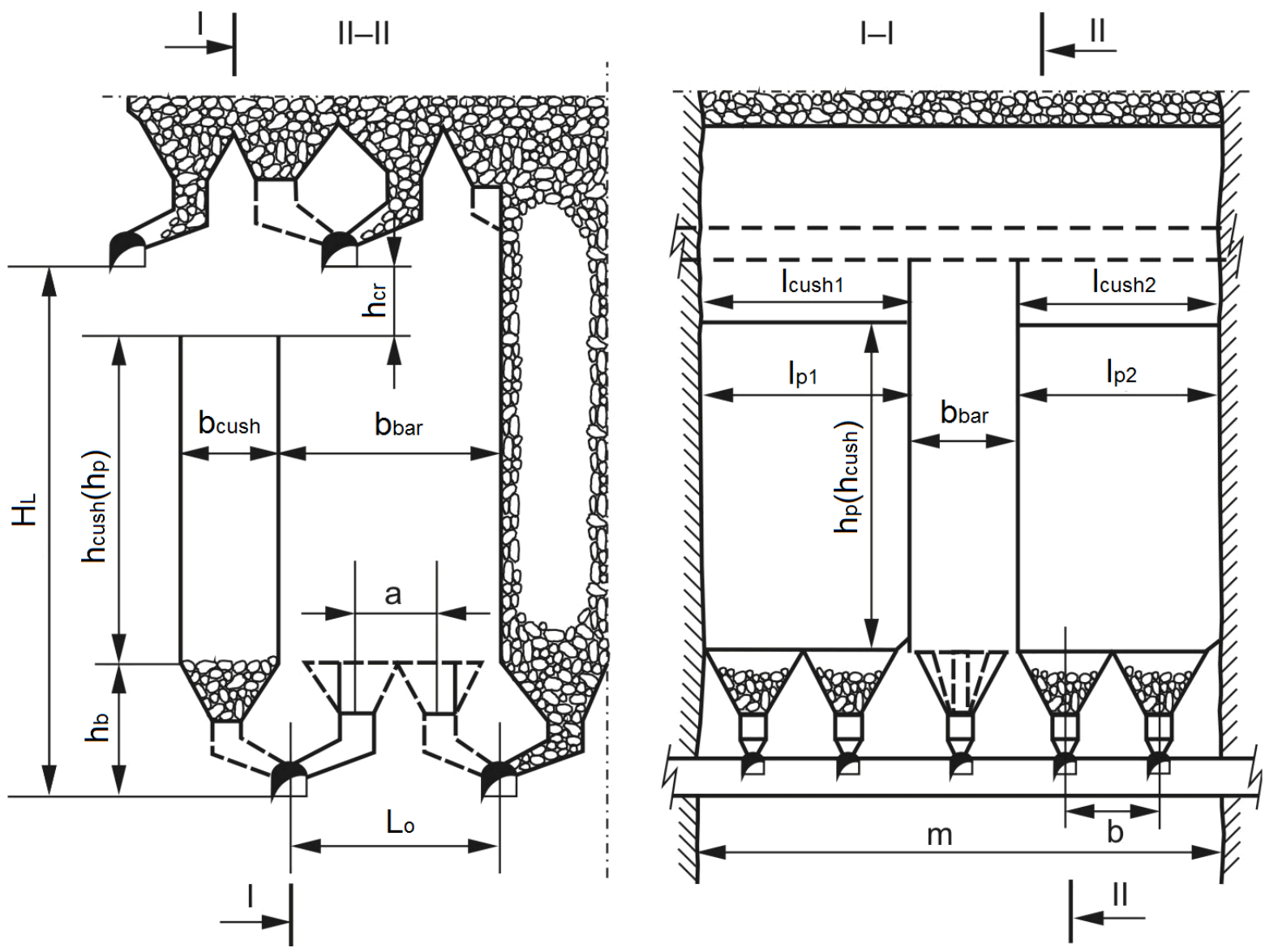

Figure 3 Layout of sublevel caving: $\mathrm{HL}$ - height of a level; $(\mathrm{m})$ orebody thickness; (hb) height of the bottom; (hcr) height of the crown; (hcush) height of the cushion; (hp) height of the pillar; (bcush) width of the cushion chamber; (bbar) spacing of the blocks (barrier); (lp) length of the pillar; (lcush) length of the cushion chamber; (Lo) spacing of the crosscuts; (a) spacing of the drawpoints; (b) spacing of the chambers where ore is loaded to cars by shakers

The process flow sheet developed for the transfer to mining with cemented backfill involves formation of an artificial barrier pillar and a separation ore pillar. The ore reserves in the safety pillars are to be extracted in stopes $70 \mathrm{~m}$ high, $27 \mathrm{~m}$ long, $13.5 \mathrm{~m}$ wide, with mined out voids filled with cemented backfill.

\section{$2 \quad$ Transition from mining with caving to mining with cemented backfilling}

Locations for the separation ore pillar and the artificial barrier pillar are designed based on the requirements of stability of the ore pillar and the backfill-made barrier pillar for the period of active mining, minimum ore loss in the pillars during the transition period, and minimum cost of the mining with cemented backfilling.

The mathematical modelling using the boundary integral equations allowed understanding of stresses in the rock mass on the north side of the orebody and inelastic strain zones that appear in weak and strong rocks as stoping is advanced (Figure 4). The location of the inelastic strain zones was accounted for in the development of process flow sheets. 


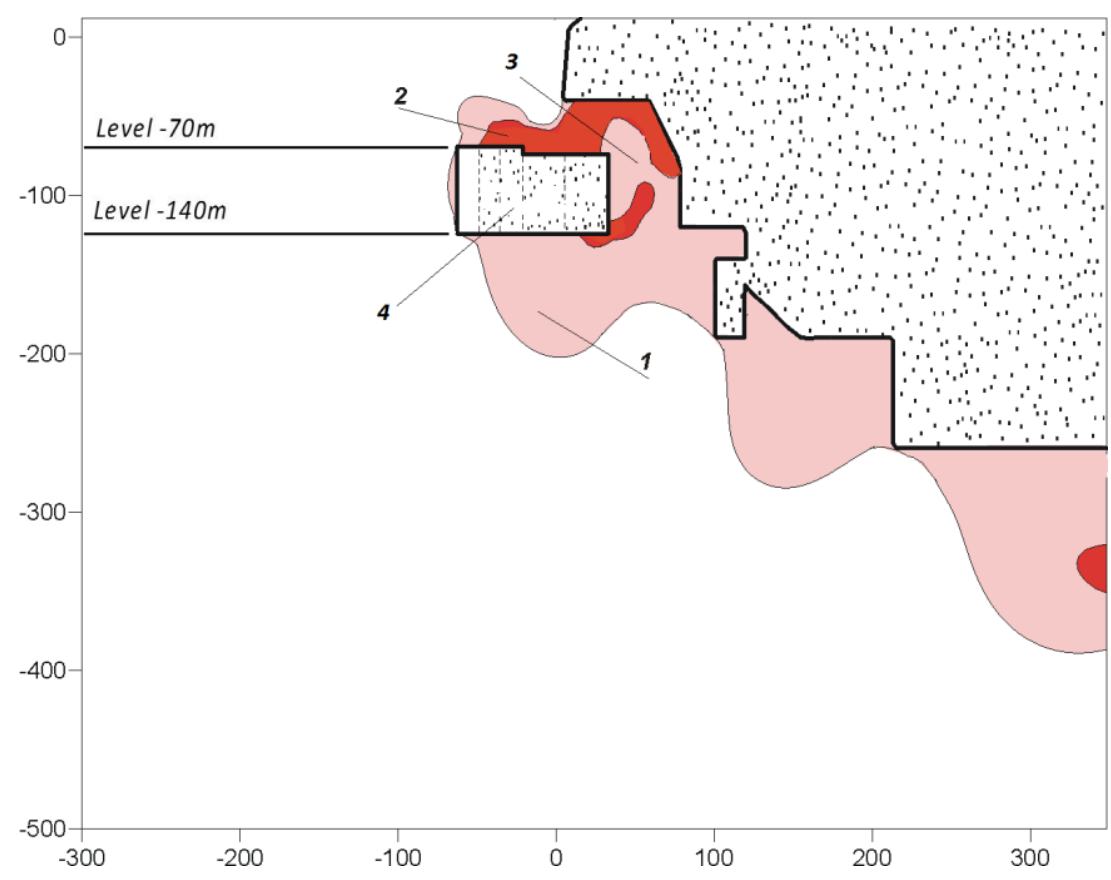

Figure 4 Inelastic strain zones in influence area of stoping on Level $(-140)-(-70) \mathrm{m}$; weak rocks (1); and hard rocks (2), separation pillar (3); stopes (4); -300-300 m - X coordinate; 0$500 \mathrm{~m}-\mathrm{Y}$ coordinate (depth below sea level)

The separation ore pillar covers ore block no. 2 (see Figure 5(a); block no. 2 is denoted as crosscut 2, and is situated between Level $-140 \mathrm{~m}$ and Level $-70 \mathrm{~m}$. Henceforth, block 1 is crosscut 1, etc. (a block includes a few stopes); and ore block no. 1 on Level (-140)-(-70) $\mathrm{m}$ and ore blocks no. 2 and no. 3 on Level $(-210)-(-150) \mathrm{m}$ as shown in Figure 5. The ore in the separation pillar on Level $(-140)-(-70) \mathrm{m}$ is extracted after formation of the artificial barrier blocks nos. 01 and 02 on Level (-140)-(-70) $m$ and artificial barrier blocks nos. 01 and 1 on Level (-210)-(-14) m. Block no. 2 is extracted by caving; block no. 1 is mined with stopes and backfill. Block no. 1 is mined first.

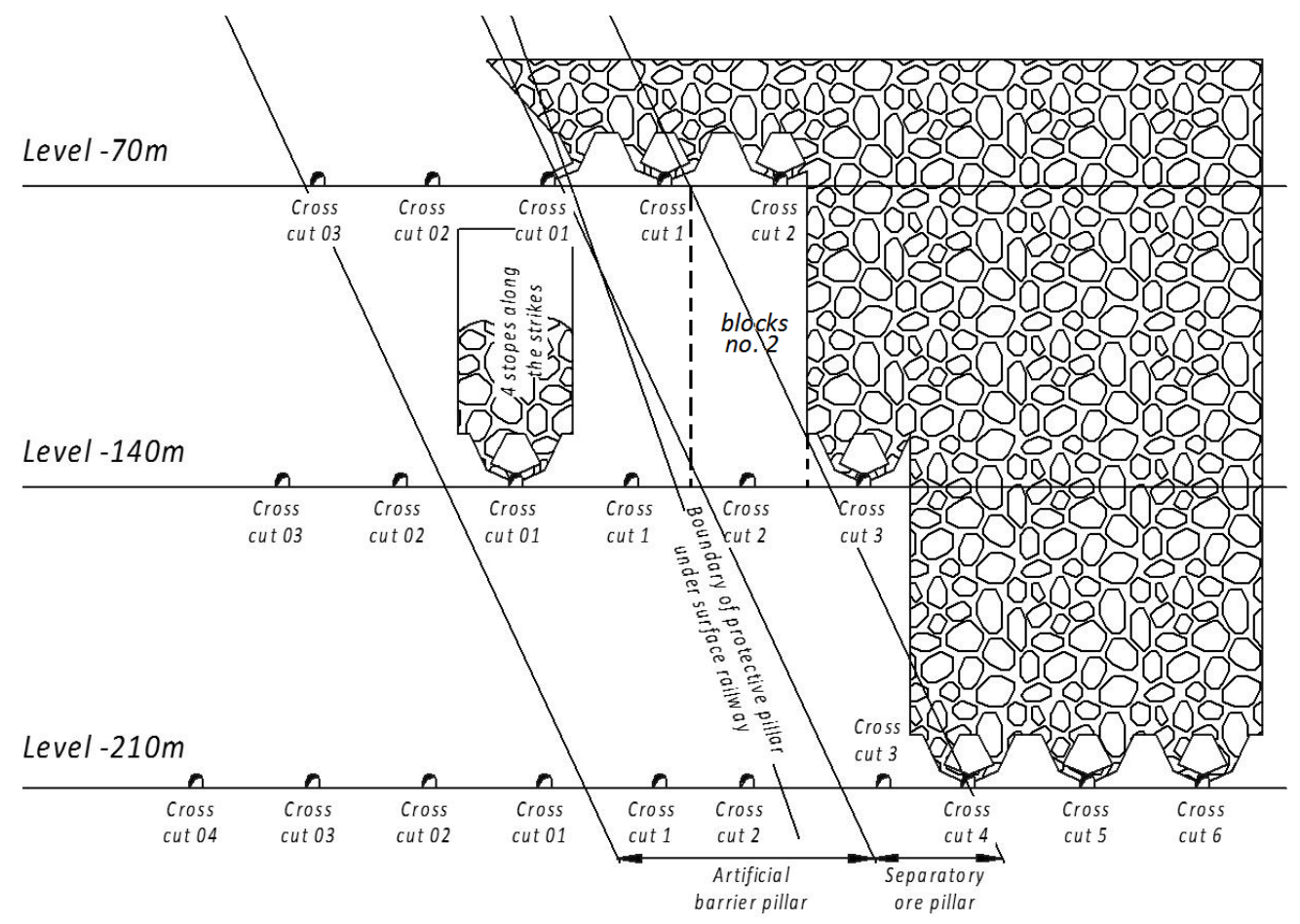

(a) 


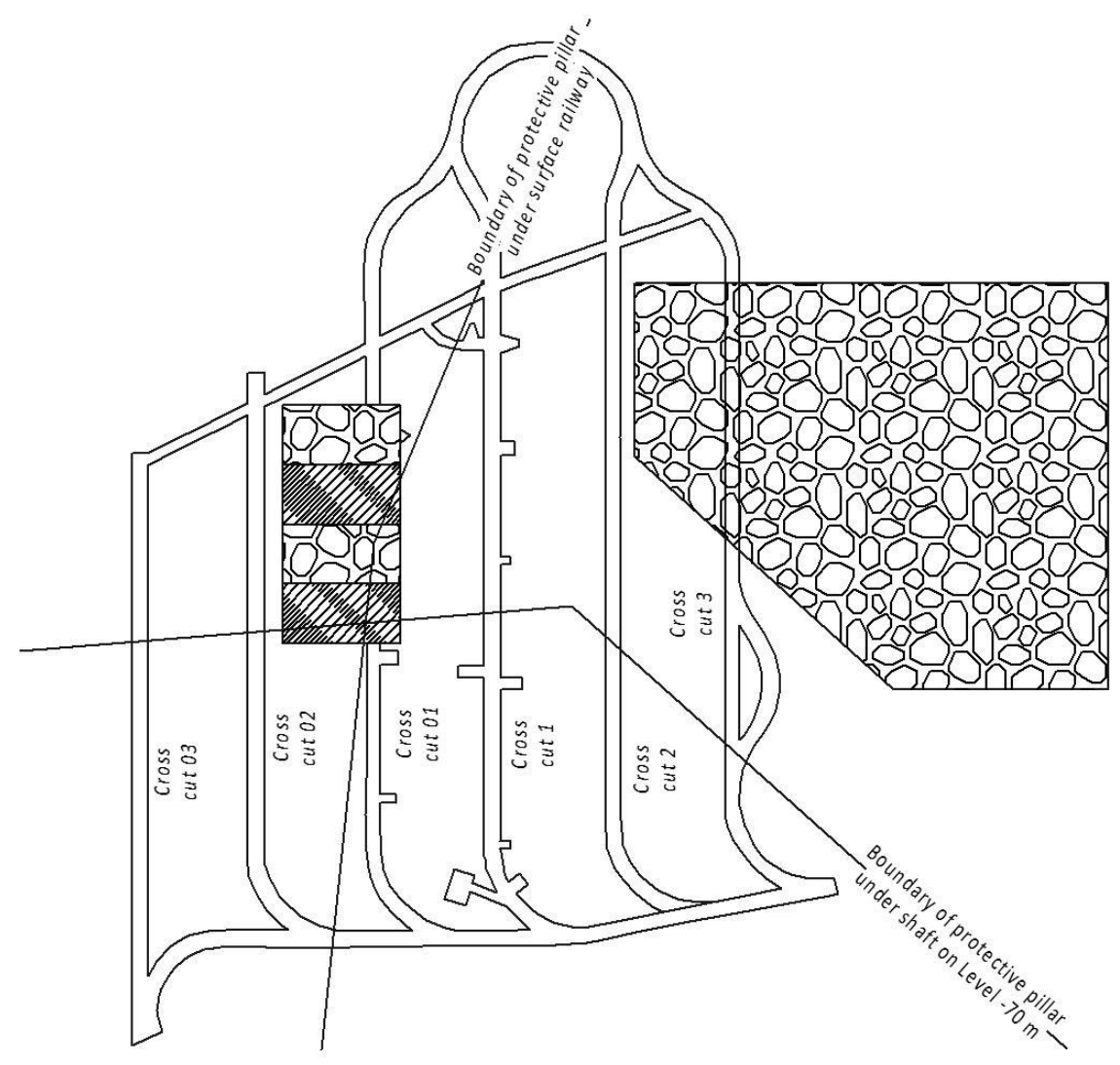

(b)

Figure 5 Transition period stage I; (a) profile; (b) plane view of Level -70 m

The artificial barrier pillar $54 \mathrm{~m}$ wide is formed in the course of mining in levels, with stopes $70 \mathrm{~m}$ high, $27 \mathrm{~m}$ long and $13.5 \mathrm{~m}$ wide. In block no. 01 to be mined first, the stopes are arranged so that their long sides are along the strike of the orebody. Block no. 2 is extracted by caving; block no. 1 is mined with stopes and backfill. Block no. 1 is mined first. On the south of block no. 01, the perimeter is made concave in order to ensure sustained stability under high ground pressure. The concavity in the centre is calculated from the formula (Eremenko et al. 2008):

$$
B_{C}=0.03 \cdot m \cdot \sqrt{\frac{\sigma}{\left.\sigma_{\text {comp }}\right]}}=0.03 \cdot 67.5 \cdot \sqrt{\frac{435}{10}}=7.12 \mathrm{~m}
$$

Where:

$$
\begin{aligned}
& m=\text { ore thickness, } \mathrm{m} . \\
& \sigma \quad=\text { tress across the strike of the orebody in the stoping area, MPa. } \\
& \sigma_{\text {comp }}=\text { ultimate strength of the fill mass in three months, MPa. }
\end{aligned}
$$

Block no. 02 is extracted with stopes arranged so that their long sides lie across the strike of the orebody. In the artificial barrier pillar on Level $(-210)-(-140) \mathrm{m}$, the technology of the stoping in blocks no. 1, 01, 2 and 02 is the same. Depending on the stoping advance rate and efficiency of the stoping with cemented backfill, extraction of block no. 1 on Level $(-210)-(-140) \mathrm{m}$ can be fulfilled earlier than extraction of block no. 1 on Level $(-140)-(-70) \mathrm{m}$.

The validated sequence of mining on Level $(-140)-(-70) \mathrm{m}$ and $(-210)-(-140) \mathrm{m}$ is as follows:

- Stage I: stoping with cemented backfill in block no. 01 (Figure 5).

- Stage II: extraction of blocks 02 and 03 on Level (-140)-(-70) m (Figure 6). 


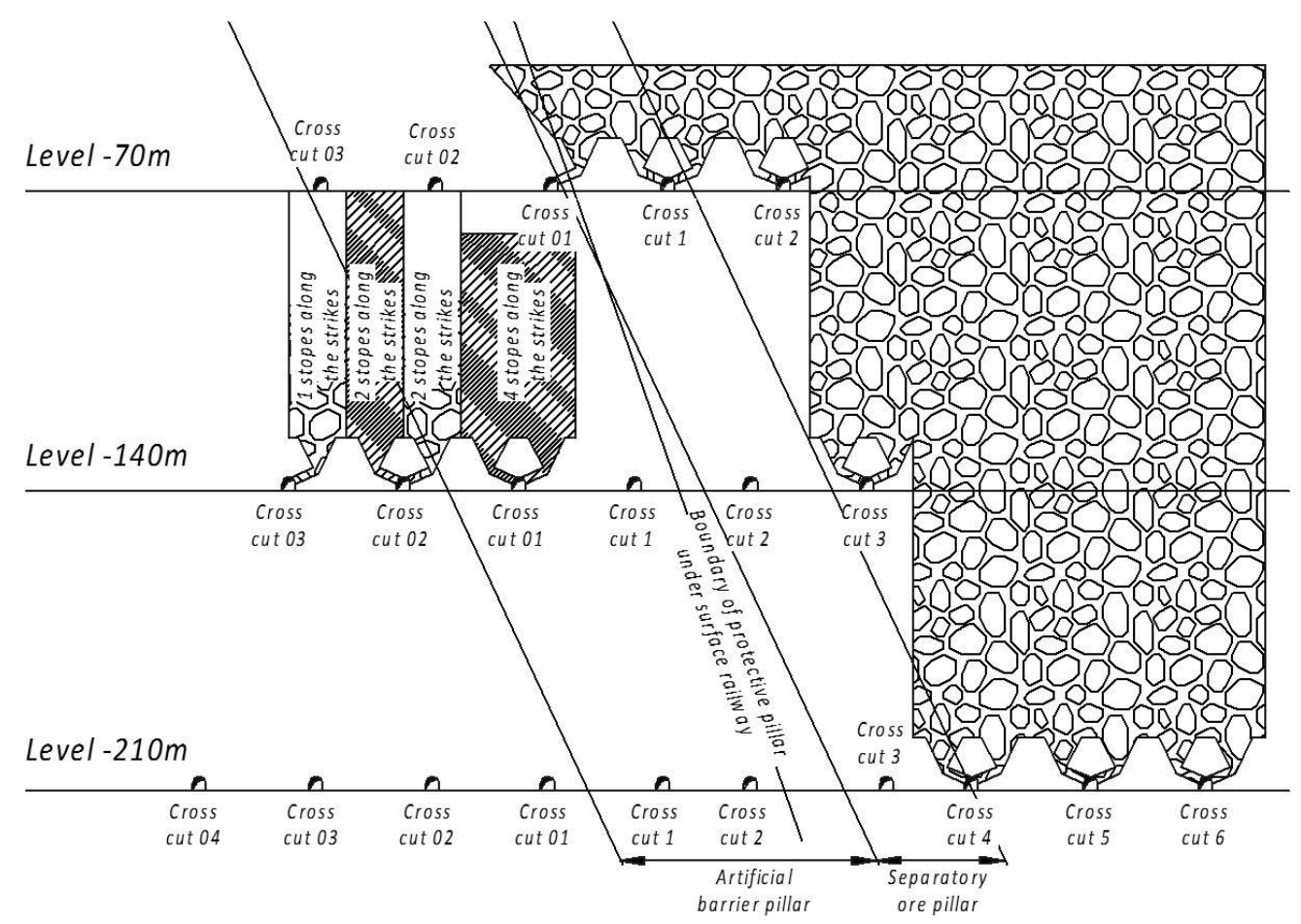

(a)

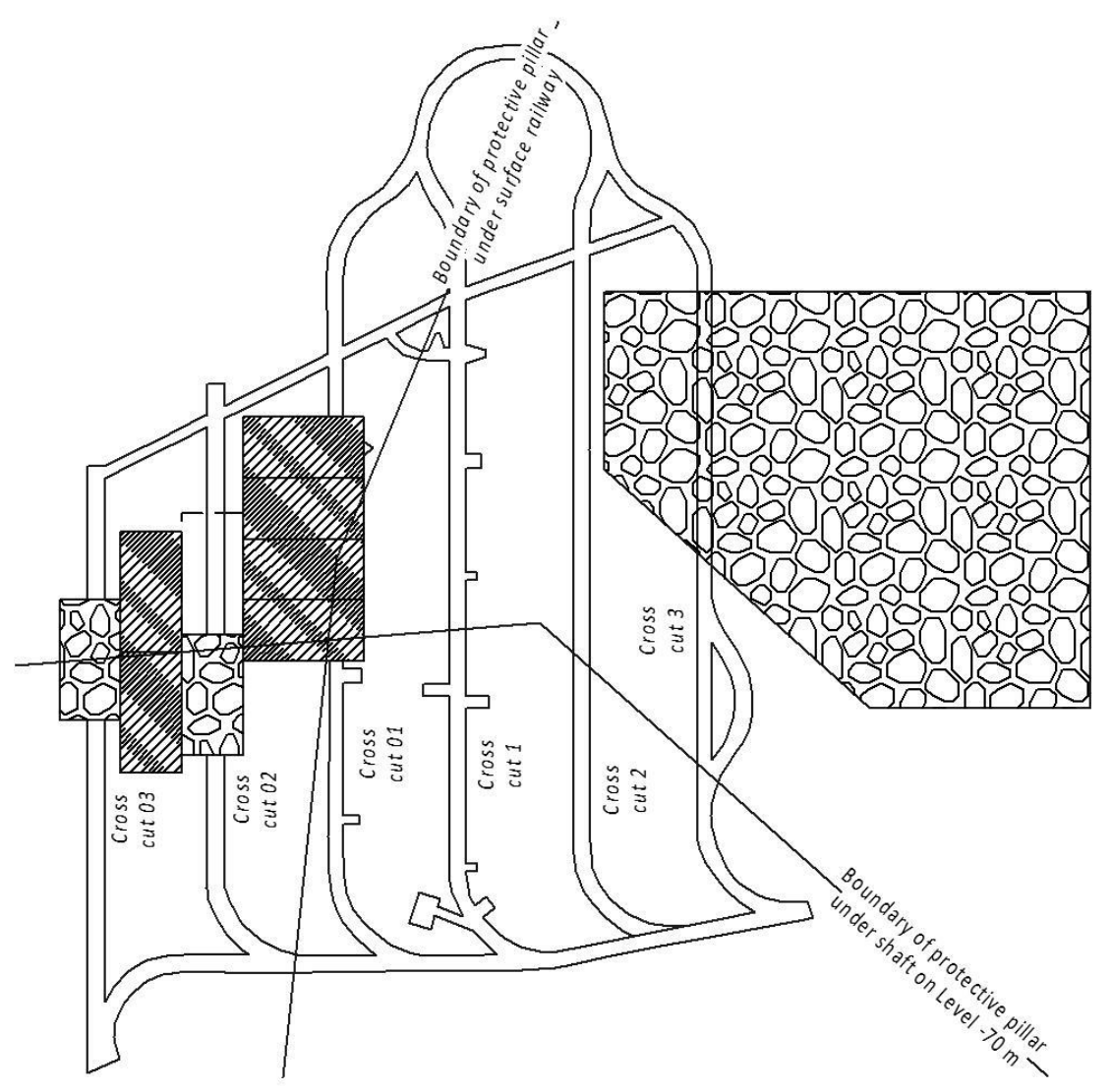

(b)

Figure 6 Transition period stage II; (a) profile; (b) plane view of Level -70 m

Stage III: reversed extraction, towards zone of caving on Level $(-210)-(-140) \mathrm{m}$. For the complete extraction of the pillars and making tops of the stopes arrow-headed, the location of crosscuts on Level $-210 \mathrm{~m}$ is shifted by $6.5 \mathrm{~m}$ relative to Level $-140 \mathrm{~m}$, and the artificial barrier pillar is formed in block no. 1 on 
Level $(-140)-(-70) \mathrm{m}$. The end faces of the adjacent stopes are made so that the surface of the barrier is concaved on the side of the separation pillar. The concavity is designed to be $7.12 \mathrm{~m}$ (Figure 7).

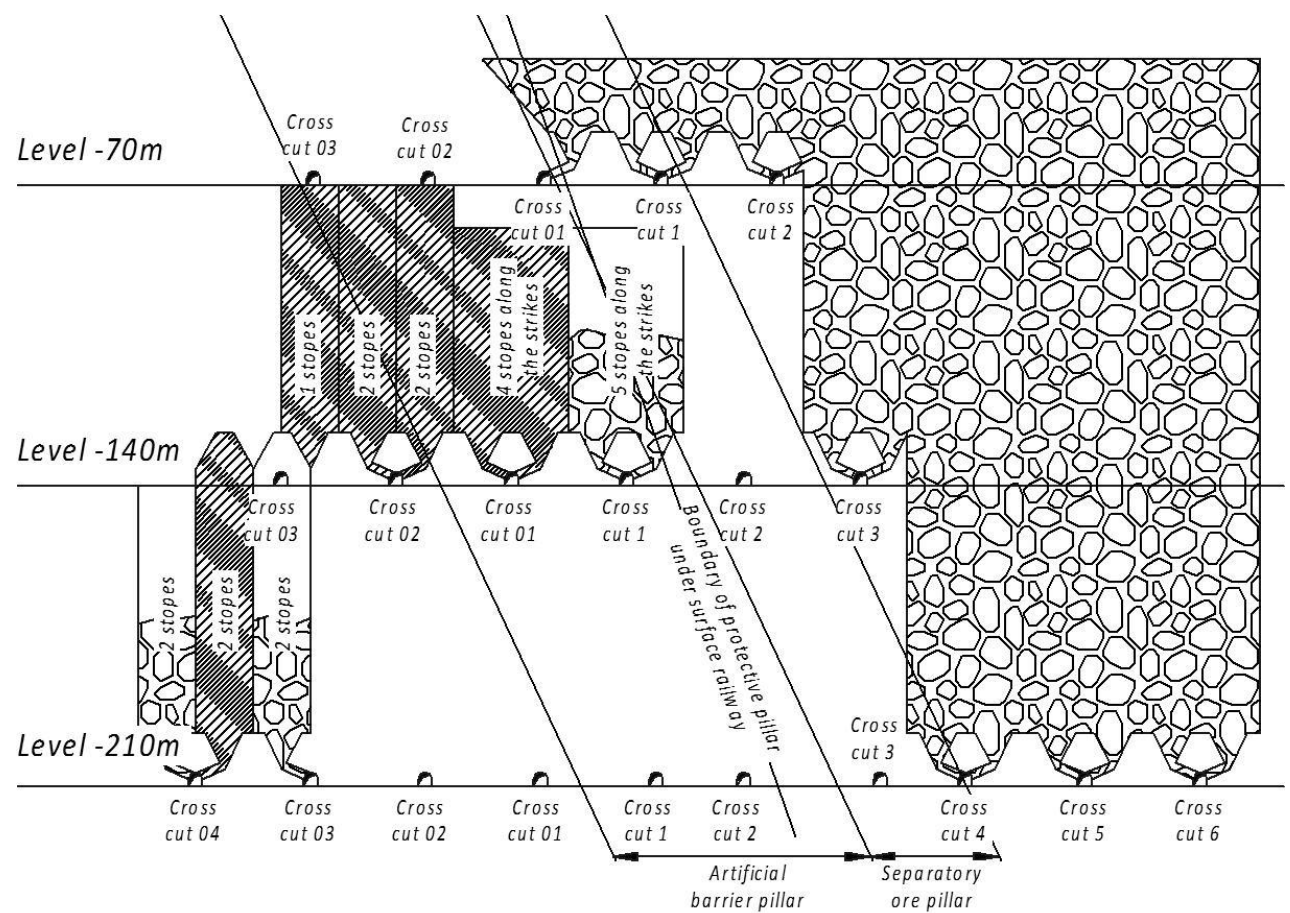

(a)

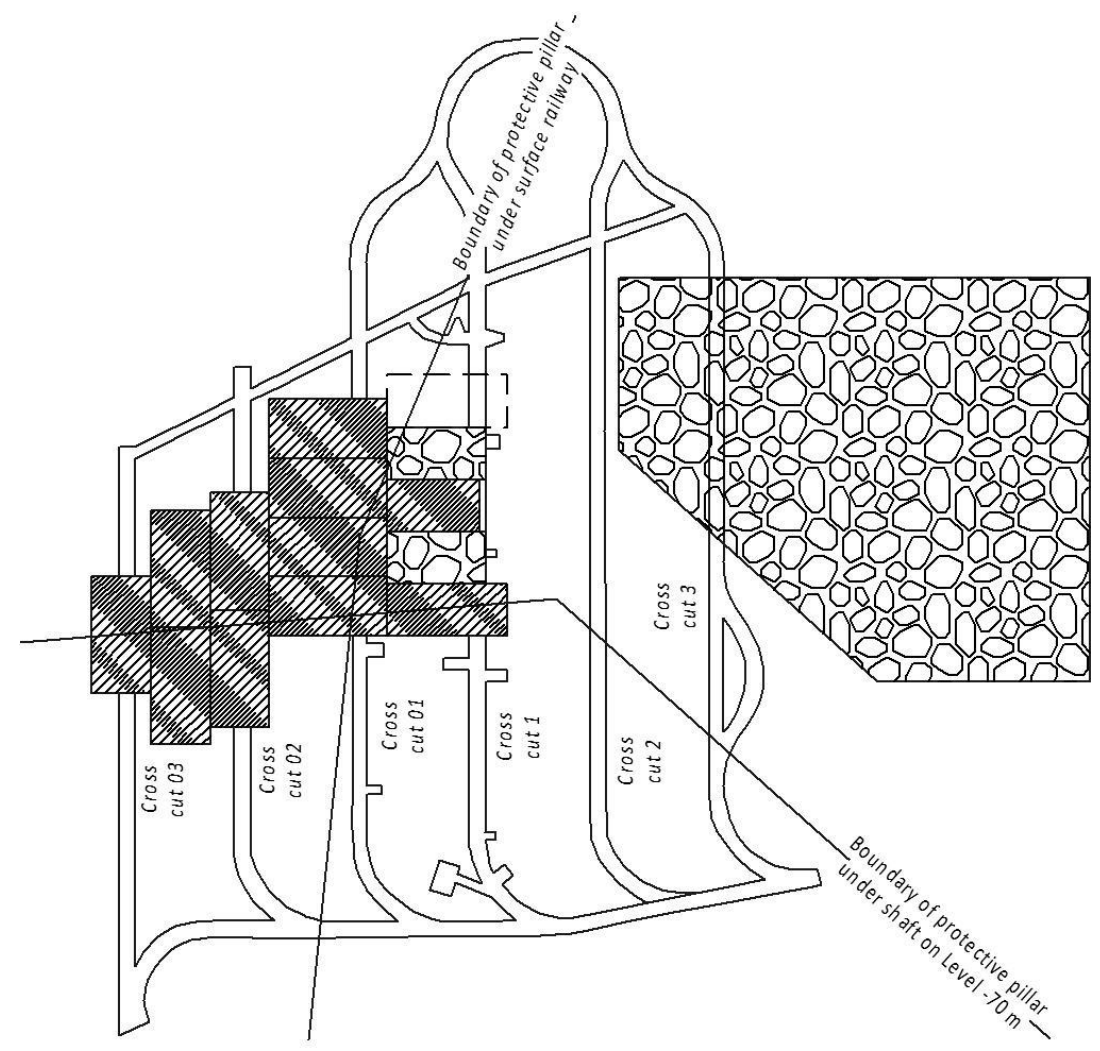

(b) 


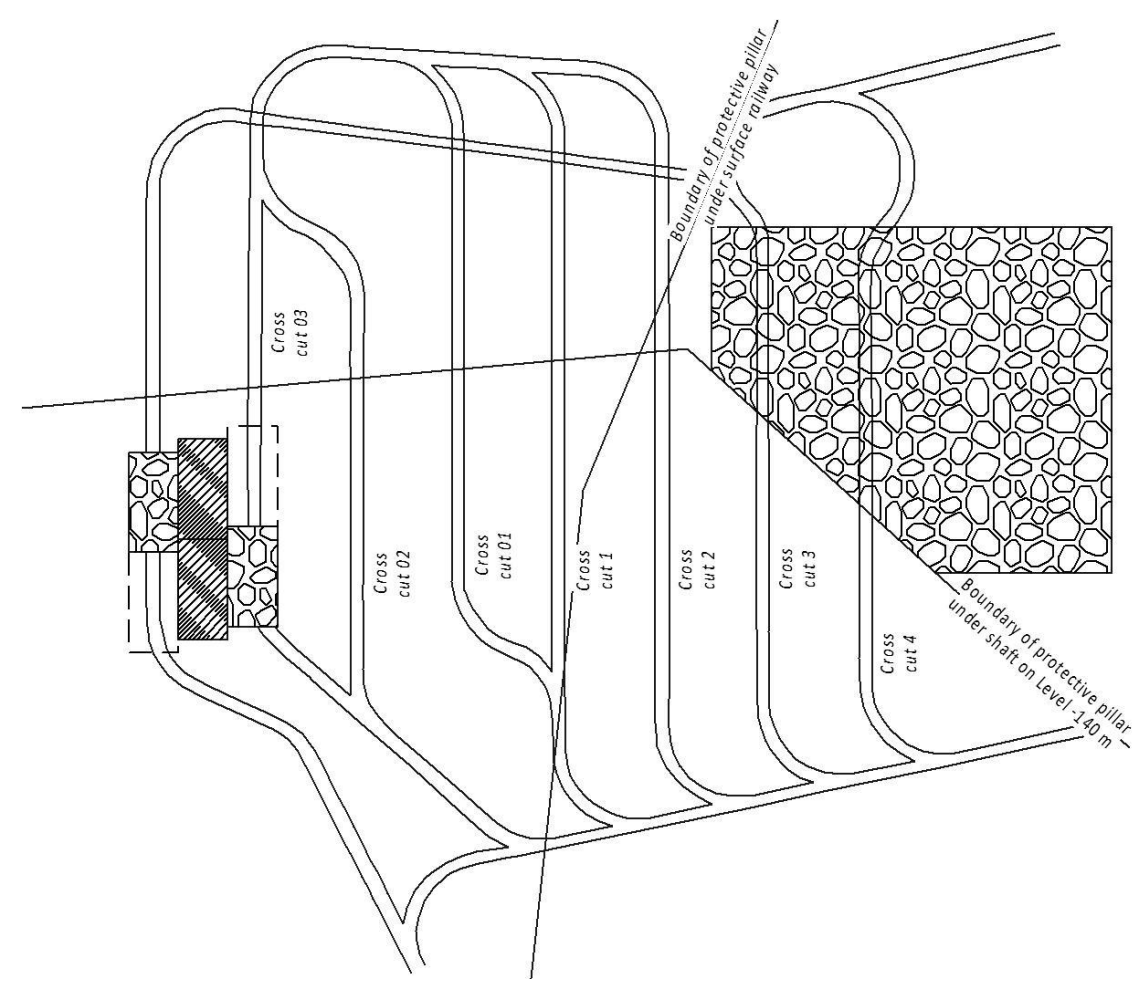

(c)

Figure 7 Transition period stage III; (a) profile; (b) plane view of Level -70 $\mathrm{m}$; (c) plane view of Level -140 m

Stage IV: extraction on Level (-210)-(-140) $\mathrm{m}$ and formation of the artificial barrier pillar in block no. 1, with arrangement of stopes along the strike of the orebody. After the stoping in block no. 1 has been completed, the artificial barrier pillar is formed in block no. 2 (Figure 8).

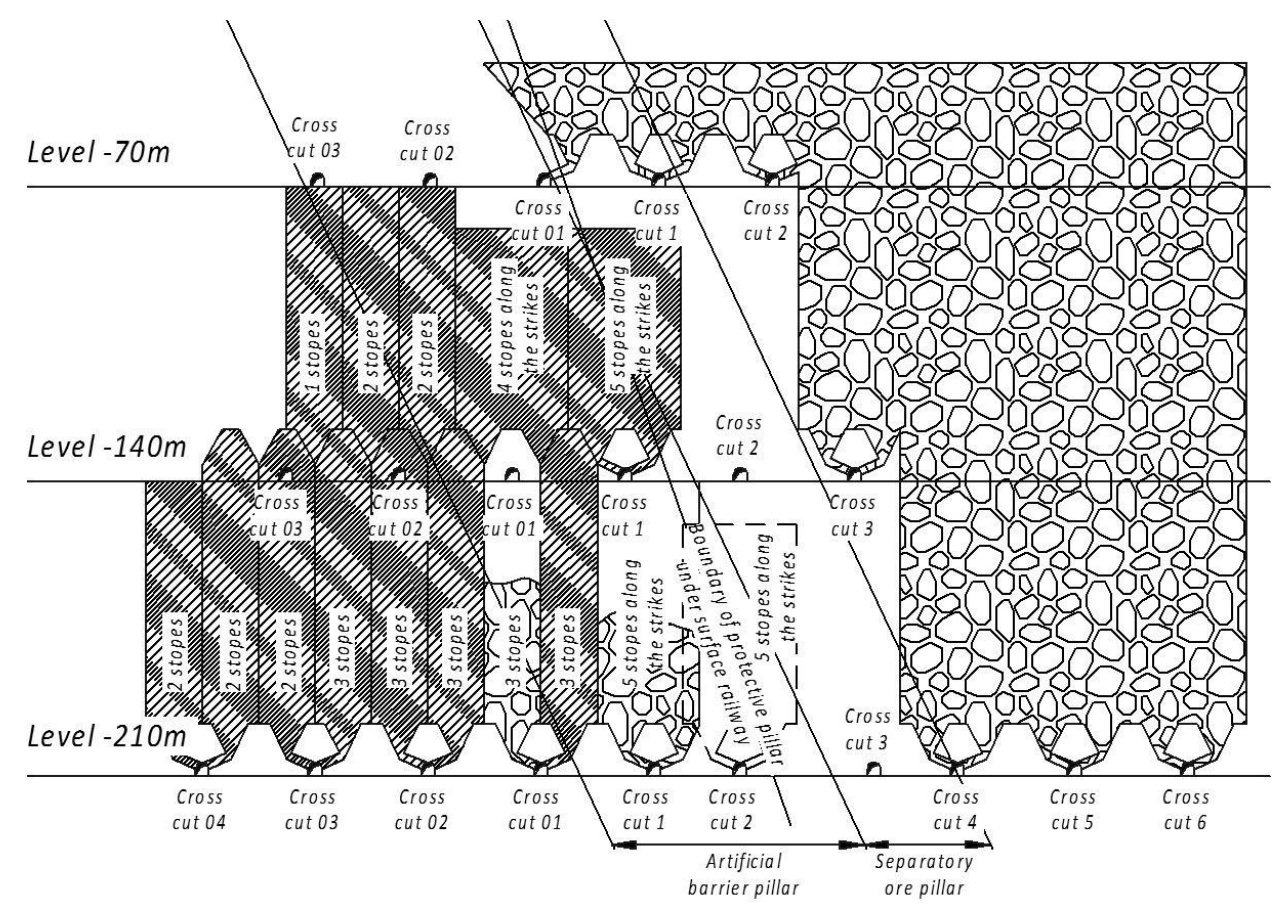

(a) 


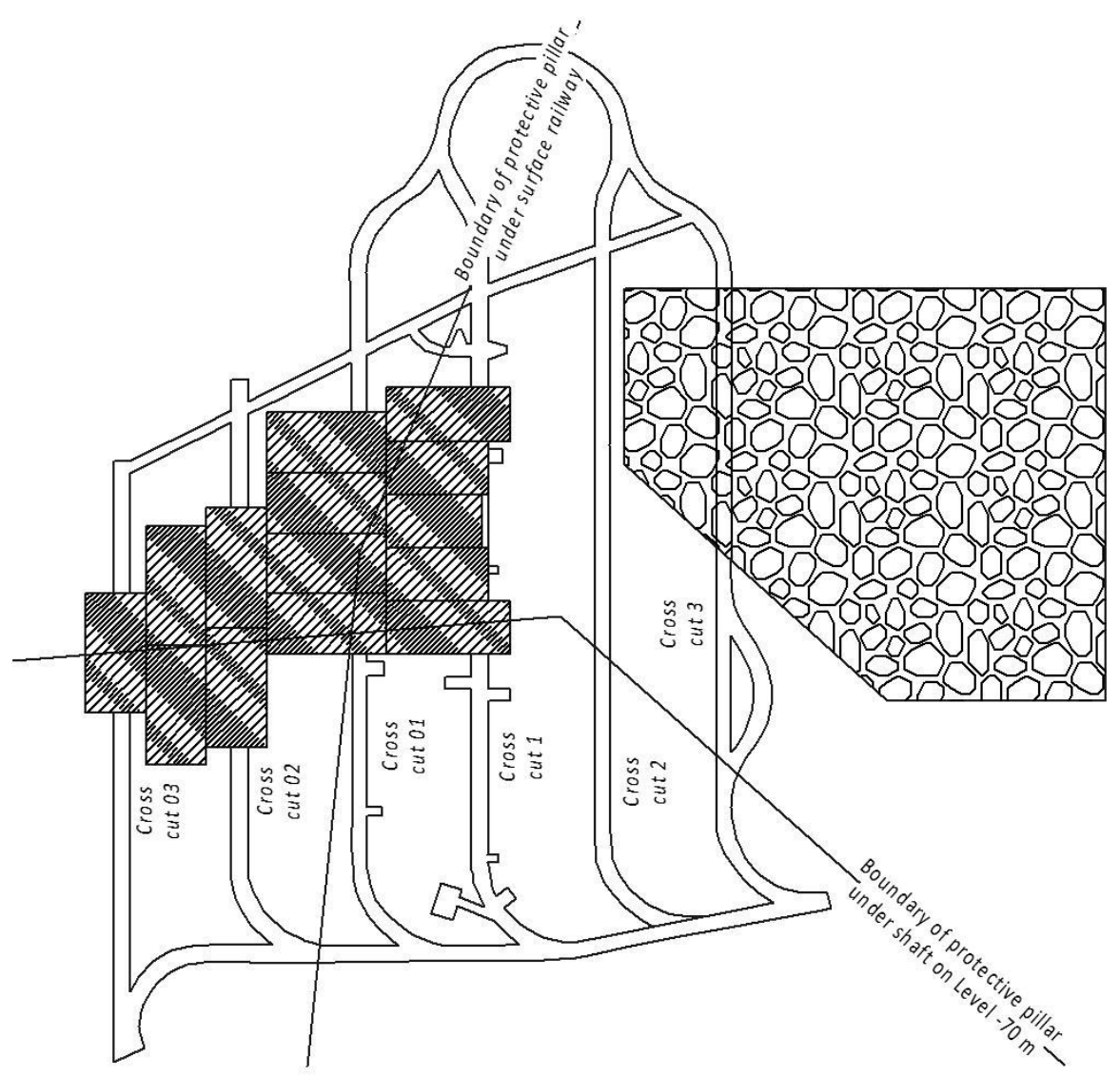

(b)

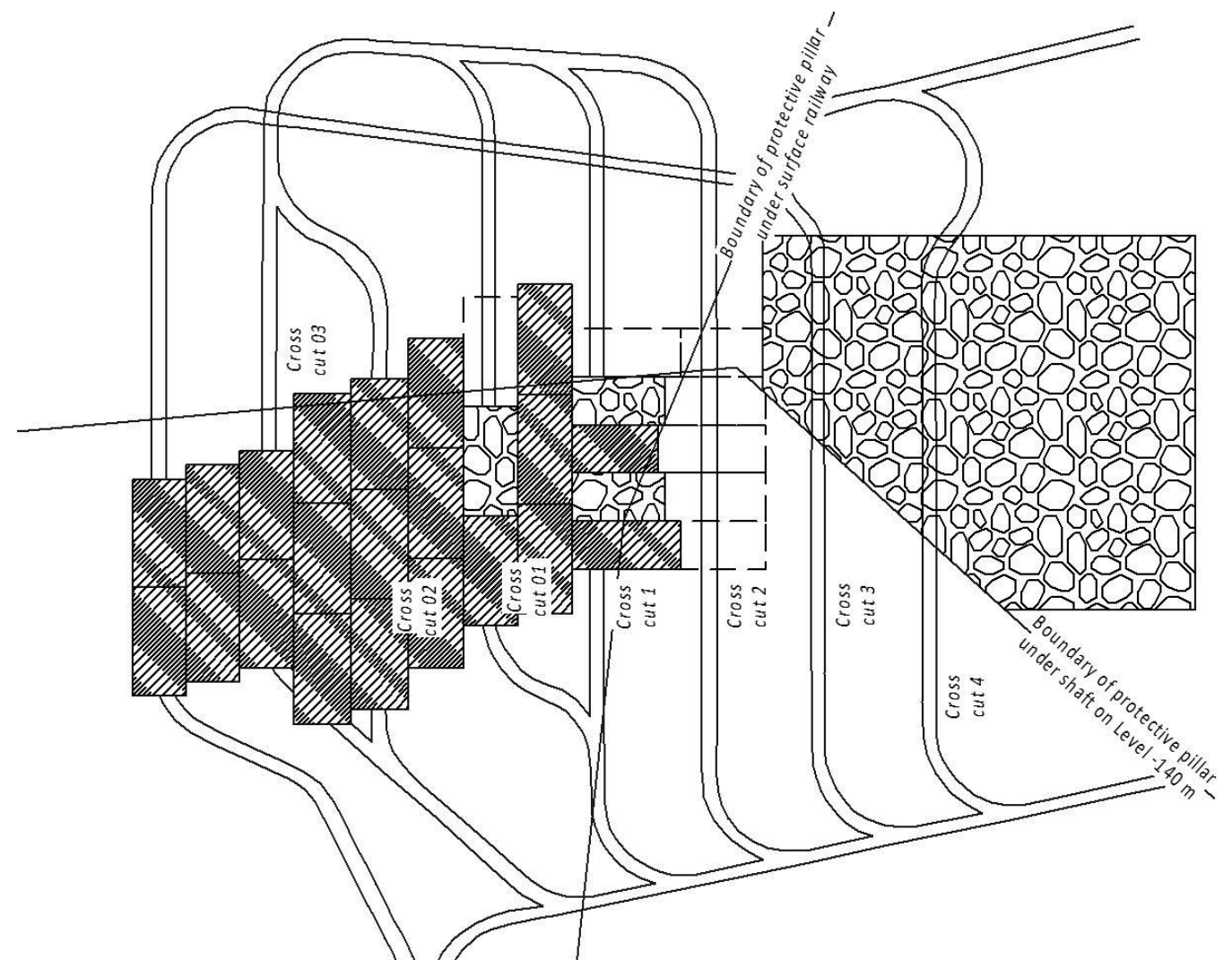

(c) 


\section{Figure 8 Transition period stage IV; (a) profile; (b) plane view of Level -70 m; (c) plane view of Level -140 m}

The design solutions on the mining sequence on Level (-140)-(-70) $m$ and Level $(-210)-(-140) m$ enable stabilisation of geodynamic situation in rock mass before high-rate stoping with cemented backfill, provision of the design dimensions of the artificial barrier pillar and preservation of the protective pillar.

\section{Preparation of cemented backfill in the Tashtagol Mine}

Profitability of the cemented backfill technology is governed by the expenditures related to the acquisition of source materials. The cemented backfill is a man-made uniform mixture of a mineral binder, a fill and water. The binder and water, after hydration transformations, become a cemented mixture that finally passes into petrous state. Introduction of the fill (gravel, broken rock, sand etc.) into the binder and water mix decreases consumption of the binder, reduces deformation on curing and increases consolidation, density and strength of the backfill owing to mitigating effect of heat-and-moisture-induced conversions during curing.

The Tashtagol Mine saves on binder costs. The mine uses granulated furnace slag from metallurgical integrated iron-and-steel works located near the mine. The fine fill material is from the closely-spaced quarries (high cost of sand affects the cost of mining); the coarse fill material is taken from accumulated tailings of the mine owned crushing and concentration plant.

To activate hydraulicity of granulated slag and fly ash, the mine uses alkaline activators (Portland cement, lime) and sulfate activators (gypsum and various combinations of anhydrite $\mathrm{CaSO}_{4}$ ). For better pumping ability and placeability, as well for reduction of spreadability, plasticisers are added to the backfill.

The effect of plasticisers and water on the flowability of cemented backfill with coarse filler $(0-20 \mathrm{~mm})$ is illustrated in Figure 9. Addition of sulphide-spirit distiller's soluble (SSDS) in an amount of $0.3 \%$ of the weight of a binder greatly improves flowability of the backfill (Figure 9(a)). Besides, it is possible to reduce water consumption by $16-20 \%$, or binder consumption, without affecting the design characteristics of the backfill. The SSDS enables higher strength of the backfill just after three months of curing, and the effect of SSDS is even more pronounced after longer curing periods. The optimised portion of SSDS addition in a backfill mixture is $0.2-0.25 \%$ of the weight of a binder. 


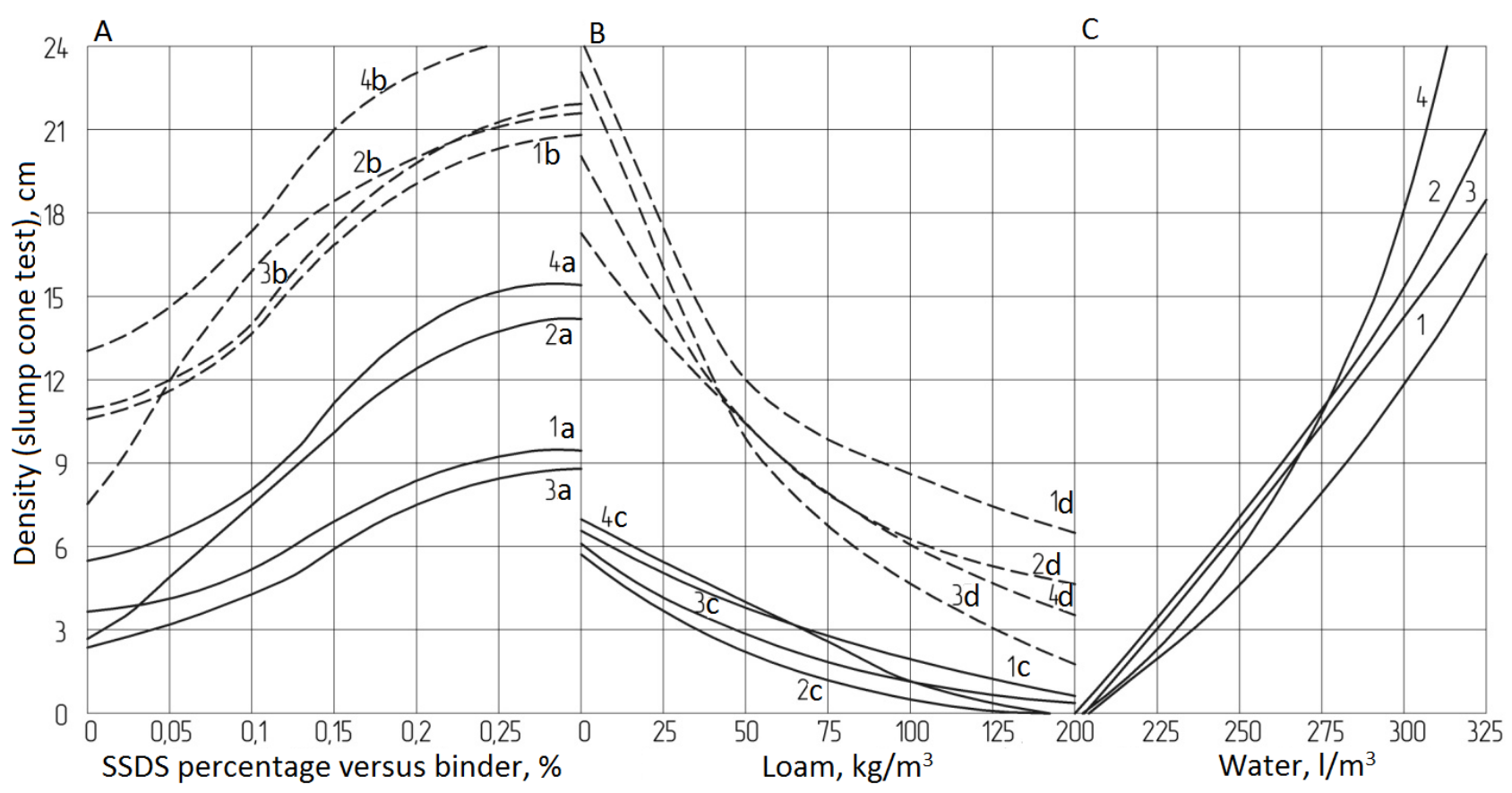

Figure 9 Flowability of the backfill mixture versus amount of plastifier and water, with the filler $520 \mathrm{~mm}$ in size;

$1,2,3,4$ - binder 200, 300, 400, $500 \mathrm{~kg} / \mathrm{m}^{5}$, respectively; a, b, c, d - water 240, 250, 270, $300 \mathrm{l} / \mathrm{m}^{3}$, respectively

Clayey material improves the pumping quality of backfill, prevents segregation, decreases resistance to motion in pipes and mitigates the pipe wear, but, unfortunately, decreases the backfill flowability (Figure $9($ b)). The decrease in the backfill flowability takes place with the clayey material addition up to $100 \mathrm{~kg}$ per cubic metre. In this case, water consumption increases by $4-5 \%$ as compared with the backfill without additions and by $19-20 \%$ as compared with the backfill with the addition of SSDS. The possibility of adding a clayey material to the backfill mixture will be decided upon the feasibility study.

The increased amount of water in the backfill mixture directly influences the backfill flowability, irrespective of the binder consumption (Figure 9(c)). With more water consumed, the backfill flows better with the binder consumption not less than $500 \mathrm{~kg} / \mathrm{m}^{3}$ (Figure 9(c), curve 4).

Backfill placed in underground mined out voids hardens and incurs pressure from enclosing rock mass (Ryzhkov et al. 1985). As mining goes to deeper levels, load on the backfill increases with time and can reach the stress of an intact rock mass. Different from the enclosing rocks in its physico-mechanical properties, fill mass withstands high compression pressure without failure.

With higher load per unit area, the cemented backfill experiences deformation (Figures 10 and 11). Under rapid continuous compression, the uniaxial strain changes in direct proportion to the stress in the backfill mixtures without clayey material addition (Figure 10, curve 1). At the stress of $60 \mathrm{MPa}$ the strain curves level-off. 


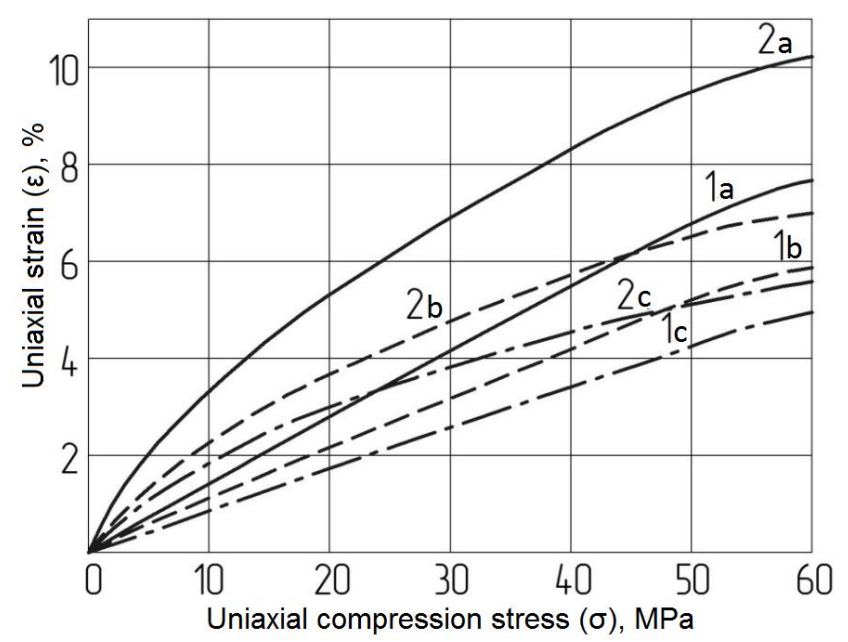

Figure 10 Straining of the backfill mixture under rapidly growing stress after (a) $28,(90)$ and (c) 180 days of curing;

1 and 2 are for mixture formulations 1 and 2

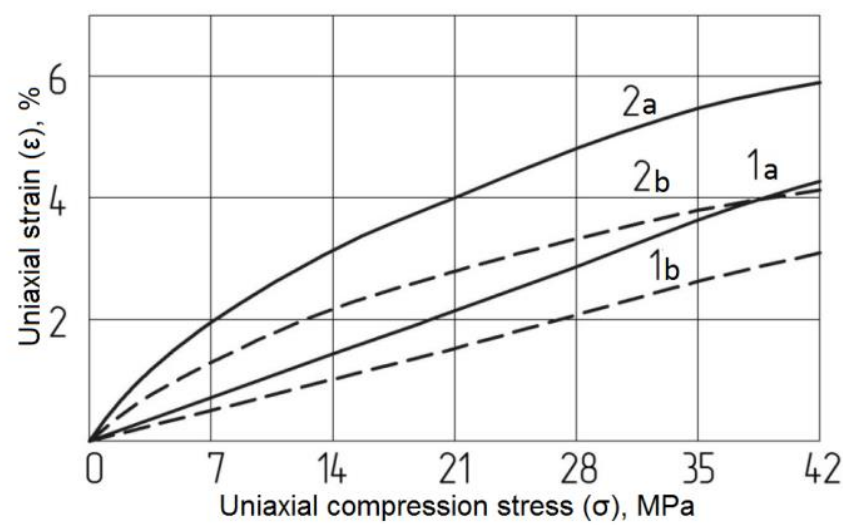

Figure 11 Straining of the backfill mixture under slowly growing stress after (a) 28, (90) and (c) 180 days of curing;

1 and 2 are for mixture formulations 1 and 2

Straining of the backfill without clayey material addition (mixture formulation 2 in Figure 10) does not follow the direct proportionality, but also levels-off under the stress of $60 \mathrm{MPa}$.

Strains in the backfill are influenced by the pattern of the backfill loading. When the loading is slow, $0.2 \mathrm{MPa}$ per day (Figure 11), the strain is lower as compared with the rapid continuous loading growth at the rate of $5 \mathrm{MPa} / \mathrm{min}$ (Figure 10).

The curing time of the backfill in the Tashtagol Mine is 90 days. Aimed at reaching the design strength of $4 \mathrm{MPa}$ and above during 90 days of curing, the cemented backfill consumes $60 \mathrm{~kg} / \mathrm{m}^{3}$ cement and $400 \mathrm{~kg} / \mathrm{m}^{3} \mathrm{slag}$, at the backfill density $2 \mathrm{t} / \mathrm{m}^{3}$.

The manufacturing parameters of the backfill are: density $1.95-2.2 \mathrm{t} / \mathrm{m}^{3}$; solid content $86-72 \%$; grinding fineness $70 \%$ of $0.14 \mathrm{~mm}$ size; pack compression $5 \%$; spreading $5 \pm 1 \%$.

The pattern and rate of the pressure application on the cemented backfill in the course of ore extraction in the Tashtagol steel thick orebody is under study, in full-scale conditions, using various methods of stress-strain state assessment and ground control. 


\section{$4 \quad$ Conclusions}

The designed and validated scenario of the transfer from mining with caving to mining with cemented backfill in the Tashtagol Mine enables ore extraction at the designed capacity of the mine.

Owing to the proposed engineering solutions on the sequence of block extraction, the geodynamic situation in deep rock mass exposed to high horizontal stress $(5 \mathrm{\gamma H})$ has been stabilised before high rate mining with cemented backfill started, the artificial pillar has been formed with the designed dimension, and the protective pillars have been kept stable.

The application of backfilling has become feasible, without the risk of collapse of mined out voids at the boundary with the protective ore pillars. Finally, the problems of the transition from mining with caving to stoping with backfill have been successively solved in the mine.

\section{References}

Bronnikov, DM, Zamesov, NF \& Bogdanov, GI 1982, Deep level ore mining, Nedra, Moscow, in Russian.

Eremenko, AA, Eremenko, VA \& Gaidin, AP 2008, Improvement of rockburst-hazardous iron ore mining under natural and mining-induced impacts, Nauka, Novosibirsk, in Russian.

Eremenko, VA, Eremenko, AA, Gakhova, LN \& Klishin, IV 2012, 'Finding zones of stress concentrations and seismic events in deep ore mining affected by high horizontal stresses', in Y Potvin (ed.), Proceedings of the Sixth International Seminar on Deep and High Stress Mining, Australian Centre for Geomechanics, Perth, pp. 443-50.

Ryzhkov, Y, Volkov, AN \& Gogolin, VA 1985, Mechanics of fill masses and their formation technology, Nedra, Moscow, in Russian. 